\title{
ANALISIS WAKTU BONGKAR MUAT PETIKEMAS PADA ALAT SHIP TO SHORE (STS) CRANE DI TERMINAL TELUK LAMONG
}

\author{
*Ashury dan Jessica Indah Pricilla \\ Departemen Teknik Kelautan Universitas Hasanuddin \\ *ashuryunhas@unhas.ac.id
}

\begin{abstract}
Abstrak
Setiap tahunnya penggunaan petikemas semakin meningkat. Masalah bongkar muat di terminal petikemas seringkali menjadi objek tinjauan berkaitan dengan kinerjanya. Studi ini menganalisa kinerja sistem pelayanan di Terminal Teluk Lamong yang ditekankan pada fasilitas Ship to shore (STS) crane dengan rumusan masalah bagaimana waktu pergerakan alat STS Crane dalam menangani bongkar muat petikemas dan apakah pelayanan bongkar muat petikemas pada alat STS Crane telah beroperasi secara maksimal. Tujuan penelitian ini adalah untuk mengetahui waktu bongkar muat petikemas dan kinerja alat Ship to shore (STS) crane di Terminal Teluk Lamong. Penelitian ini menggunakan metode deskriptif. Sumber data yang digunakan adalah data primer diambil dengan cara mengamati, mewawancarai, dan mengukur langsung waktu pelayanan alat STS Crane dengan durasi waktu \pm 1 jam. Data sekunder diperoleh dengan mengutip dokumen pada instansi yang bersangkutan seperti data jumlah fasilitas alat, kapasitas alat, umur alat, dan layout Terminal Teluk Lamong. Hasil analisis diketahui bahwa kinerja waktu pelayanan Ship to shore (STS) crane cukup baik. Hal ini dilihat dari pelayanan STS Crane tertinggi adalah STS 04D pada proses muat sebesar 25 box/STS/jam, sedangkan pelayanan STS Crane terendah adalah STS 03I pada proses muat 18 box/STS/jam. Berdasarkan data diperoleh kesimpulan bahwa kinerja waktu pelayanan Ship to shore (STS) crane masih dapat ditingkatkan lagi, sehingga kapasitas produksi mencapai maksimal.
\end{abstract}

Kata Kunci: Ship To Shore (STS) Crane, Effective Time Dan Idle Time, Kinerja Bongkar Muat.

\begin{abstract}
Abstrct
Every year the use of containers is increasing. The loading and unloading problem at the container terminal is often the object of review regarding its performance. This study analyzes the performance of the service system at the Teluk Lamong Terminal which emphasizes the Ship to Shore (STS) crane facility with the formulation of the problem of how the movement time of the STS tool Crane in handling container loading and unloading and whether the container loading and unloading service on the STS Crane is operating optimally. The purpose of this study was to determine the time of loading and unloading of containers and the performance of the Ship to Shore (STS) crane at Lamong Bay Terminal. This research uses a descriptive method. The data source used is primary data taken by observing, interviewing, and measuring directly the service time of the STS tool Crane with a duration of \pm 1 hour. Secondary data is obtained by quoting documents from the relevant agencies such as data on the number of equipment facilities, the capacity of tools, age of tools, and layout of Teluk Lamong Terminal. The results of the analysis show that the performance of the Ship to Shore (STS) crane service time is quite good. This can be seen from the highest STS Crane service is STS 04D at loading process of 25 boxes/STS/hour, while theSTSservice Crane lowest STS 03I at 18 boxes/STS/hour loading process. Based on the data, it is concluded that the performance of the Ship to Shore (STS) crane service time can still be improved, so that the production capacity reaches a maximum.
\end{abstract}

Keyword: Ship To Shore (STS) Crane, Effective Time Dan Idle Time, Loading and Unloading Performance. 


\section{PENDAHULAN}

Peran angkutan laut di Indonesia yang merupakan negara kepulauan adalah sangat penting. Angkutan barang melalui laut sangat efisien dibanding moda angkutan darat dan udara. Kapal mempunyai daya angkut lebih besar daripada kendaraan darat dan udara. Hampir semua barang impor, ekspor dan muatan dalam jumlah sangat besar diangkut dengan menggunakan kapal laut. Wilayah Indonesia yang begitu luas membuat perkembangan daerah disebagian wilayah Indonesia menjadi kurang merata. Sebagai pintu masuk perdagangan dan juga jalur distribusi barang lainnya terhadap suatu daerah maka diperlukan adanya suatu pelabuhan serta terminal petikemas yang memadai yang berguna untuk mengakomodasi proses distribusi tersebut.

Kinerja pelabuhan dapat digunakan untuk mengetahui tingkat pelayanan pelabuhan kepada pengguna pelabuhan (kapal dan barang), yang tergantung pada waktu pelayanan kapal selama berada di pelabuhan. Kinerja pelabuhan yang tinggi menunjukkan bahwa pelabuhan dapat memberikan pelayanan yang baik [1].

PT Terminal Teluk Lamong merupakan anak perusahaan dari PT Pelabuhan Indonesia III (Persero) yang berkonsep ramah lingkungan dan semi otomatis. Pada dasarnya, pelayanan Terminal Teluk Lamong berorientasi kepada beberapa kebijakan dasar yaitu: efesiensi biaya, efektifitas waktu, dan juga kepuasan pelanggan. Perkembangan kualitas pelayanan Terminal Teluk Lamong juga didukung oleh ketersediaan fasilitas dan peralatan yang modern, serta sumber daya manusia dengan kualitas yang tinggi mampu memberikan pelayanan yang cepat, tepat, dan aman [2].

PT Terminal Teluk Lamong dilengkapi dengan peralatan-peralatan canggih yang mendukung modernisasi dan otomatisasi pelayanan jasa kepelabuhanan. Terminal ini mengusung konsep Go Green dengan menggunakan bahan bakar gas dan meminimalkan emisi dari keseluruhan proses bisnisnya. Arus container yang melalui Terminal Teluk Lamong semakin meningkat. Hal ini dapat dilihat dari pertumbuhan bongkar muat petikemas (container) dari tahun ke tahun. Begitu besarnya potensi Transhipment barang yang terjadi di lapangan menuntut adanya peningkatan sisi pelayanan baik sisi operasional maupun sisi fasilitas [3].

Pertumbuhan bongkar muat di Terminal Teluk Lamong cukup signifikan. Pada semester pertama tahun 2017. Arus produksi petikemas Terminal Teluk Lamong mencapai 217.363 TEUs meingkat 92,5 persen dibanding dengan produksi tahun sebelumnya, yaitu sebesar 112.879 TEUs pada periode yang sama. Peningkatan yang signifikan terlihat pada arus perikemas internasional. Tahun 2016, pada semester pertama, arus perikemas internasional Terminal Teluk Lamong sebesar 52.678 TEUs. Sedangkan pada semester pertama tahun 2017 mencapai sebesar 116.331 TEUs. Terjadi peningkatan produksi sebesar 120,8 persen. Pada arus petikemas domestik juga terjadi kenaikan produktivitas sebesar 67,8 persen dibanding periode yang sama tahun sebelumnya [4].

Oleh karena itu kinerja alat bongkar muat petikemas dalam hal ini Ship to Shore (STS) crane harus diperhatikan khususnya dalam kecepatan dan kesiapan muatan di pelabuhan agar pelayanan dapat terlaksana secara maksimal, untuk mendapatkan target produksi yang maksimal, sehingga perusahaan bisa mendapatkan laba dengan biaya produksi yang semakin rendah. Dengan alasan tersebut penulis mengangkat topik penelitian dengan judul yang berhubungan dengan Ship To Shore Crane yaitu "ANALISIS WAKTU BONGKAR MUAT PETIKEMAS PADA ALAT SHIP TO SHORECRANE DI TERMINAL TELUK LAMONG (Studi Kasus Di PT. Terminal Teluk Lamong)".

\section{METODE}

Untuk Lokasi penelitian ini adalah di PT Terminal Teluk Lamong wilayah PT. Pelabuhan Indonesia III (Persero) yang berada di Jawa Timur dan pengambilan data dilakukan selama 1 bulan. Penelitian ini menggunakan metode penelitian deskriptif yang bertujuan untuk mencatat, mengelola, menyajikan dan mengiterpresentasikan dan untuk memberikan gambaran secara jelas.

\subsection{Data Primer}

Terdiri dari tahap 1: proses mengambil dan mengunci petikemas di atas kapal, tahap 2: proses mengangkat petikemas di atas kapal dan tahap 3: spreader bergeser dan menurunkan petikemas dari kapal ke atas combined terminal tractor trailers (CTT) dan melepaskan kunci di atas combined terminal tractor trailers (CTT) tahap 4: mengembalikan posisi spreader ke posisi awal yang diperlukan. 


\subsection{Data Skunder}

Data yang diperoleh dengan mengutip dokumen yang ada pada instansi yangbersangkutan seperti data jumlah fasilitas alat, data kapasitas alat, layout Terminal Teluk Lamong, dan lain-lain.

\section{HASIL DAN PEMBAHASAN}

Terminal Multiguna Teluk Lamong dibangun dengan kade sedalam -14 LWS dan dilengkapi peralatanperalatan canggih yang mendukung modernisasi dan otomatisasi pelayanan jasa kepelabuhanan. Pertumbuhan bongkar muat di Terminal Teluk Lamong cukup signifikan [5]. Pada semester pertama tahun 2017. Tahun 2016, pada semester pertama, arus perikemas internasional Terminal Teluk Lamong sebesar 52.678 TEUs. Sedangkan pada semester pertama tahun 2017 mencapai sebesar 116.331 TEUs. Terjadi peningkatan produksi sebesar 120,8 persen. Pada arus petikemas domestik juga terjadi kenaikan produktivitas sebesar 67,8 persen dibanding periode yang sama tahun sebelumnya, seperti ditunjukkan pada gambar berikut.

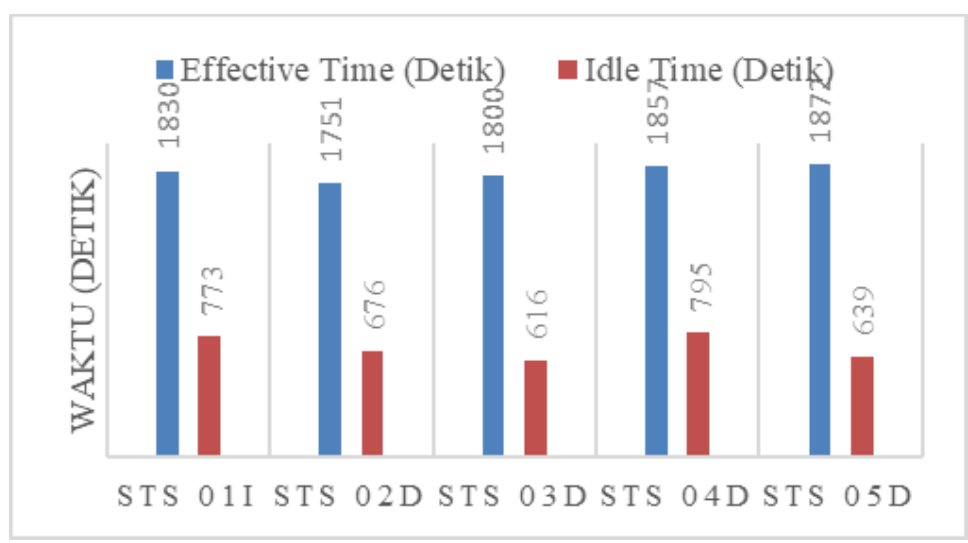

Gambar 1. Grafik Perbandingan Effective time dan Idle time STS.

Dari gambar 1 dapat diketahui bahwa effective time tertinggi pada STS 05D yaitu 1872 detik atau 31 menit. Sedangkan idle time tertinggi pada STS 04D yakni 795 detik atau 13 menit. Idle time tertinggi dikarenakan terjadi kemacetan di container yard yang menyebabkan CTT yang akan mengangkut petikemas menunggu untuk dilayani. Dari data waktu pelayanan ship to shore (STS) [6] crane pada proses bongkar dermaga domestik dapat diketahui persentase effective time dan idle time setiap STS Crane dari tabel berikut.

Tabel 1. Persentase effective time dan idle time pada setiap STS [6]

\begin{tabular}{|c|c|c|c|c|c|}
\hline & $\begin{array}{l}\text { Effective time } \\
\text { (Detik) }\end{array}$ & $\begin{array}{l}\text { Idle time } \\
\text { (Detik) }\end{array}$ & $\begin{array}{l}\text { Berth Working } \\
\text { Time (Detik) }\end{array}$ & Persentase (\%) & \\
\hline & & & & Effective time & Idle time \\
\hline STS 01I & 1830 & 773 & 2603 & 70 & 30 \\
\hline STS 02D & 1751 & 676 & 2427 & 72 & 28 \\
\hline STS 03D & 1800 & 616 & 2416 & 75 & 25 \\
\hline STS 04D & 1857 & 795 & 2652 & 70 & 30 \\
\hline STS 05D & 1872 & 639 & 2511 & 75 & 25 \\
\hline
\end{tabular}

Persentase effective time tertinggi pada setiap STS yaitu pada STS 03I dan STS 05I sebesar 75\% dan terendah pada STS 01I dan STS 04I. Sedangkan persentase tertinggi yakni pada STS 01I dan STS 04I sebesar 30\% dan terendah pada STS 03I dan STS 05I sebesar 25\% dengan tampilan grafik sebagai berikut. 


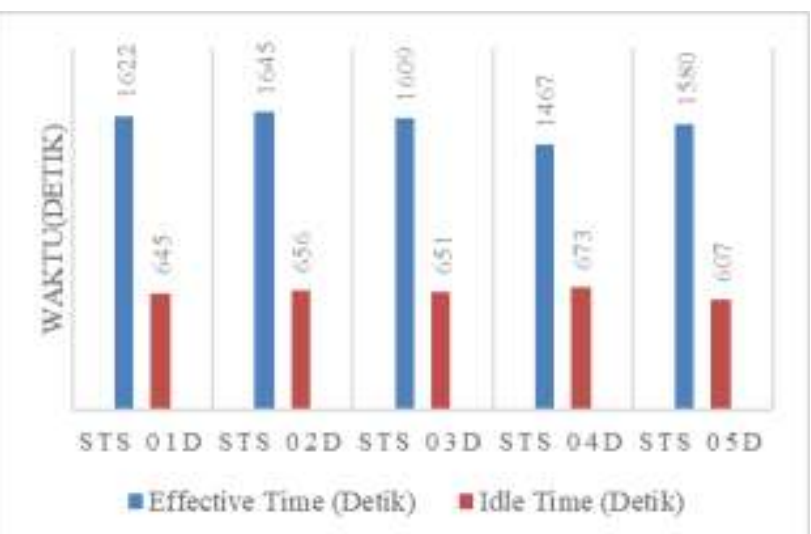

Gambar 2 Grafik Perbandingan Effective time dan Idle time STS

Berdasarkan gambar 2 diketahui bahwa effective timetertinggi pada proses muat di dermaga domestik terjadi pada STS 02D yaitu 1645 detik atau 27 menit. Sedangkan idle time tertinggi pada proses muat di dermaga domestik terjadi pada STS 04D yakni 673 detik atau 11 menit. Idle time [7] tertinggi dikarenakan terjadi kemacetan di Container Yard yang menyebabkan CTT yang akan mengangkut petikemas menunggu untuk dilayani.

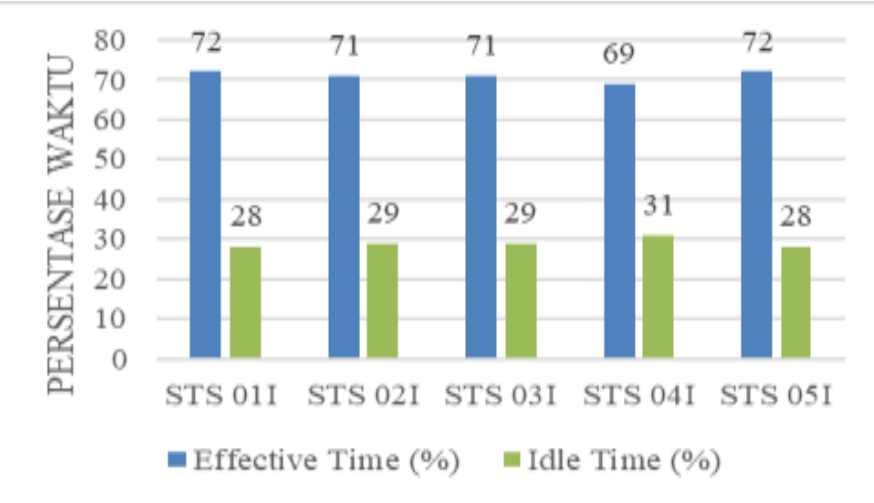

Gambar 3 Grafik persentase effective time dan idle time pada setiap STS

Dari gambar 4 diketahui bahwa persentase effective time tertinggi pada STS STS 01I dan STS 05I sebesar 72\% dan terendah pada STS 04I yakni sebesar 69\%. Sedangkan untuk persentase idle time tertinggi pada STS 04I sebesar 31\% dan terendah pada STS 01I dan STS 05I sebesar 28\%.

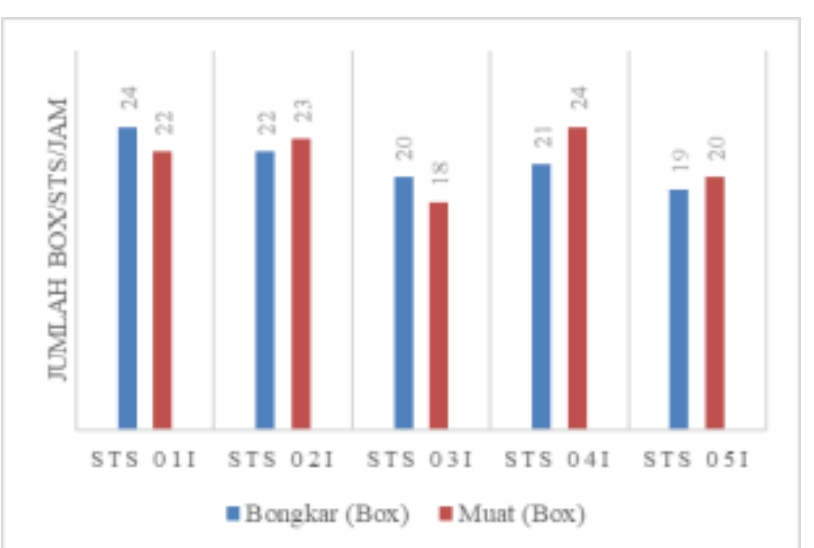

Gambar 4 Grafik Rekapitulasi Pelayanan Ship To Shore Crane pada Dermaga Internasional

Berdasarkan Gambar 4 menunjukan hasil yang dapat disimpulkan waktu rata-rata pelayanan ship to shore (STS) crane fluktuatif setiap jamnya. Pada proses bongkar hasil rekapitulasi kinerja pelayanan ship to shore (STS) crane tertinggi pada STS 01I didapatkan 24 box/STS/jam, dan rata-rata terendah dari hasil rekapitulasi pada STS 05I sebanyak 19 box/STS/jam. Pada saat proses muat hasil rekapitulasi kinerja pelayanan ship to copyright is published under Lisensi Creative Commons Atribusi 4.0 Internasional. 
shore (STS) crane tertinggi pada STS 04I didapatkan 24 box/STS/jam, dan rata-rata terendah dari hasil rekapitulasi kinerja ship to shore (STS) cranepada proses muat pada STS 03I sebanyak 18 box/STS/jam. Ratarata jumlah bongkar muat per jam sebanyak 43 Box.

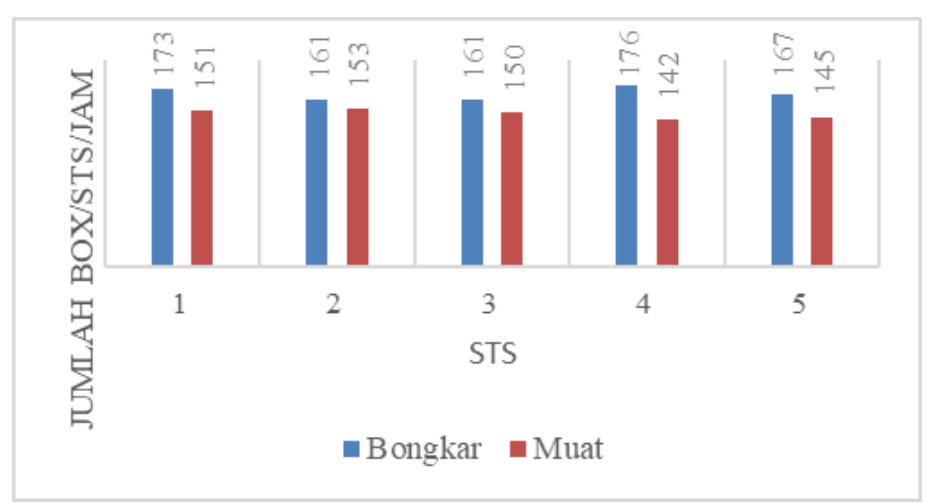

Gambar 5. Grafik Rekapitulasi Pelayanan Ship To Shore Crane pada Dermaga Domestik

Berdasarkan gambar 5 menunjukan hasil yang dapat disimpulkan waktu rata-rata pelayanan ship to shore (STS) crane fluktuatif setiap jamnya. Pada proses bongkar hasil rekapitulasi kinerja pelayanan ship to shore (STS) crane tertinggi pada STS 02D dan 03D didapatkan 22 box/STS/jam, dan rata-rata terendah dari hasil rekapitulasi pada STS 01D dan 04D sebanyak 20 box/STS/jam. Pada proses muat hasil rekapitulasi kinerja pelayanan ship to shore (STS) crane tertinggi pada STS 04D didapatkan sebanyak 25 box/STS/jam, dan ratarata terendah dari hasil rekapitulasi saat proses muat didapatkan pada STS 02D sebanyak 23 box/STS/jam. Rata-rata jumlah bongkar muat per jam sebanyak 45 box. Hasil rekapitulasi kinerja pelayanan setiap Ship to shore (STS) crane sangat bervariasi, dari pengamatan di lokasi pengambilan data. Terdapat beberapa faktor yakni, faktor lingkungan yang tidak kondusif juga sangat berpengaruh dan juga kelacaran pelayanan di Container Yard. Pada proses bongkar maupun muat memiliki kendala masing-masing pada prosesnya, tidak menutup kemungkinan hal yang terjadi dikarenakan faktor yang sama.

Adapun faktor yang dapat mempengaruhi penurunan produktivitas pelayanan alat ship to shore (STS) crane yakni idle time dan not operation time yang dialami di lokasi studi yaitu [7]:

1. Terjadinya kerusakan alat (Ship To Shore Crane)

2. Menunggu muatan,

3. Perubahan cuaca,

4. Kesalahan-kesalahan teknis lainnya.

Untuk meminimalisir lama waktu idle time faktor-faktor yang dapat mempengaruhi keterlambatan harus perlu adanya perencanaan perbaikan alat dan faktor-faktor yang mepengaruhinya secara berkala sehingga mengurangi terjadi kerusakan alat. Produktivitas bongkar muat adalah hasil/output dari kecepatan dalam penanganan dan pelayanan petikemas. Dari hasil wawancara dengan pengawai Terminal Teluk Lamongproduktivitas bongkar muat Ship to shore (STS) crane mampu menyelesaikan \pm 50.000 box/bulannya. Berikut ini adalah rekap produktivitas arus bongkar muat petikemas pada Ship to shore (STS) crane tahun 2019 pada dermaga Internasional dan Domestik. Berdasarkan tabel 4.2 dapat disimpulkan bahwa produktivitas arus bongkar muat di Terminal Teluk Lamong Tahun 2019 pada Dermaga Internasional fluktuatif setiap bulannya. Jumlah call kapal tertinggi terjadi pada bulan Agustus sebanyak 25 kapal. Untuk jumlah total box tertinggi per bulannya terjadi pada bulan Mei sebanyak 24510 box atau 34019 TEUS. Untuk ukuran container $40 \mathrm{ft}$ terdapat pada bulan Juli sebanyak 10022 box dan untuk $20 \mathrm{ft}$ sebanyak 14458 box. Berikut adalah produktivitas arus bongkar muat tahun 2019 pada Dermaga Domestik. Jika data di atas tabulasi dibuat grafik antara jumlah petikemas pada dermaga Internasional dan Domestik tiap bulannya pada tahun 2019 maka, dapat dilihat pada gambar dibawah ini.

Tabel 2. Produktivitas arus bongkar muat tahun 2019 pada dermaga Internasional [8]

\begin{tabular}{llllll}
\hline \multirow{2}{*}{ Bulan } & \multicolumn{2}{l}{ Jumlah Call } & \multicolumn{2}{l}{ Jumlah Total/Bulan } & \multicolumn{2}{l}{ Ukuran Container } \\
\cline { 2 - 6 } & Kapal & Box & Teus & $40 \mathrm{ft}$ & $20 \mathrm{ft}$ \\
\hline Januari & 23 & 19911 & 27811 & 7900 & 12011 \\
Februari & 20 & 18222 & 25336 & 7114 & 11108 \\
Maret & 24 & 21985 & 30694 & 8709 & 13276 \\
April & 17 & 16432 & 23261 & 6829 & 9603 \\
\hline
\end{tabular}

copyright is published under Lisensi Creative Commons Atribusi 4.0 Internasional. 


\begin{tabular}{llllll}
\hline \multirow{2}{*}{ Bulan } & \multicolumn{2}{l}{ Jumlah Call } & \multicolumn{2}{l}{ Jumlah Total/Bulan } & \multicolumn{2}{l}{ Ukuran Container } \\
\cline { 2 - 6 } & Kapal & Box & Teus & $40 \mathrm{ft}$ & $20 \mathrm{ft}$ \\
\hline Mei & 27 & 24610 & 34019 & 9409 & 15201 \\
Juni & 20 & 12259 & 16907 & 4648 & 7611 \\
Juli & 24 & 24480 & 34502 & 10022 & 14458 \\
Agustus & 25 & 23050 & 32701 & 9651 & 13399 \\
September & 22 & 21248 & 29799 & 8551 & 12697 \\
Oktober & 24 & 23366 & 32583 & 9217 & 14149 \\
November & 23 & 23230 & 33002 & 9772 & 13458 \\
Desember & 21 & 20984 & 29699 & 8715 & 12269 \\
\hline
\end{tabular}

Tabel 3. Produktivitas arus bongkar muat tahun 2019 pada dermaga Domestik[8]

\begin{tabular}{llllll}
\hline Bulan & Jumlah Call & \multicolumn{2}{c}{ Jumlah Total/Bulan } & \multicolumn{2}{c}{ Ukuran Container } \\
& Kapal & Box & Teus & $40 \mathrm{Ft}$ & $20 \mathrm{Ft}$ \\
\hline Januari & 58 & 23856 & 26172 & 2316 & 21540 \\
Februari & 63 & 28561 & 31199 & 2638 & 25923 \\
Maret & 67 & 28850 & 31717 & 2867 & 25983 \\
April & 54 & 23939 & 26529 & 2590 & 21349 \\
Mei & 53 & 23923 & 27160 & 3237 & 20686 \\
Juni & 46 & 18499 & 20500 & 2001 & 16498 \\
Juli & 67 & 30827 & 33300 & 2473 & 28354 \\
Agustus & 66 & 30103 & 33168 & 3065 & 27038 \\
September & 70 & 31389 & 34722 & 3333 & 28056 \\
Oktober & 69 & 31160 & 34717 & 3557 & 27603 \\
November & 64 & 26734 & 29556 & 2822 & 23912 \\
Desember & 74 & 32118 & 35380 & 3262 & 28856 \\
\hline
\end{tabular}

Berdasarkan tabel 3 dapat disimpulkan bahwa produktivitas arus bongkar muat di Terminal Teluk Lamong Tahun 2019 pada Dermaga Domestik fluktuatif setiap bulannya. Jumlah call kapal tertinggi terjadi pada bulan Desember sebanyak 70 kapal. Untuk jumlah total box tertinggi per bulannya terjadi pada bulan Desember sebanyak 32118 box atau 35380 TEUS. Untuk ukuran container $40 \mathrm{ft}$ terbanyak terdapat pada bulan Oktober sebanyak 3557 box dan untuk $20 \mathrm{ft}$ terdapat pada bulan Desember sebanyak 28856 box. Jika data di atas tabulasi dibuat grafik antara jumlah petikemas pada dermaga Internasional dan Domestik tiap bulannya pada tahun 2019 maka, dapat dilihat pada gambar dibawah ini

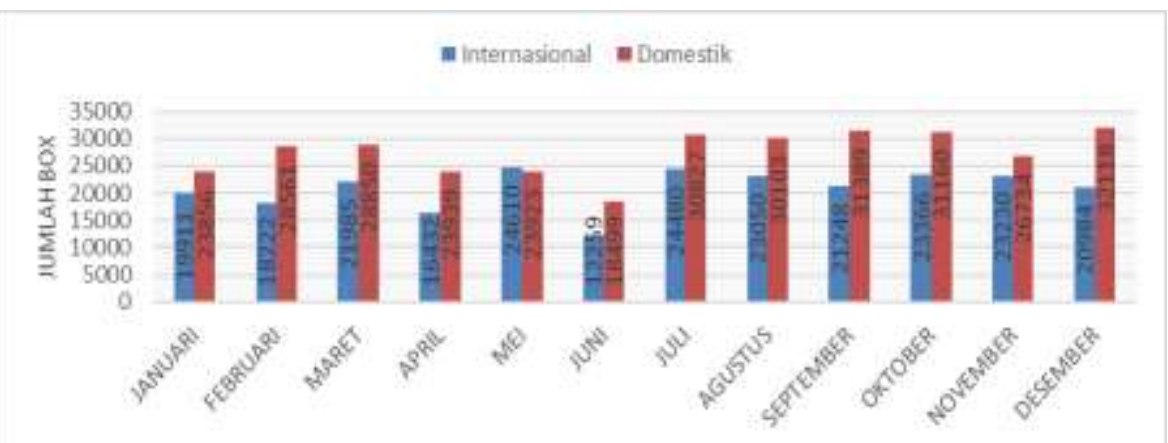

Gambar 6 Grafik kinerja pelayanan bongkar muat Ship To Shore Terminal Teluk Lamong 2019

Berdasarkan gambar 4.6 hasil rekap produktivitas bongkar muat petikemas pada alat ship to shore (STS) crane, pada tahun 2019 untuk kinerja pelayanan terbanyak terjadi pada bulan Desember yang mencapai 32118 box/bulan dan pada dermaga Internasional kinerja pelayanan terbanyak terjadi juga pada bulan Mei yang mencapai 24610 box/bulan. Selain itu juga rata-rata kinerja pelayanan bongkat muat pada dermaga Domestik mencapai 27496 box/tahun dan pada dermaga Internasional mencapai 20814box/tahun. BTP atau Daya Lalu Petikemas yaitu jumlah barang (atau box untuk petikemas) dalam satuan waktu tertentu yang melalui tiap meter panjang dermaga/tambatan yang tersedia. Untuk mendapatkan Berth Throughput atau daya lalu petikemas digunakan persamaan 2.1. Diketahui ukuran dermaga di Terminal Teluk lamong adalah 500x50 copyright is published under Lisensi Creative Commons Atribusi 4.0 Internasional. 
untuk dermaga internasional dan 450x30 untuk dermaga domestik. Dari data produktivitas arus bongkar muat di Terminal Teluk Lamong pada Tahun 2019, maka BTP dapat diketahui seperti pada tabel berikut.

Tabel 4. Daya Lalu Petikemas di Terminal Teluk Lamong pada Tahun 2019

\begin{tabular}{llll}
\hline Dermaga & Arus Petikemas & \multicolumn{2}{l}{ Daya Lalu (BTP) } \\
\cline { 2 - 4 } & (box/Tahun) & Box $/ \mathrm{m} /$ tahun & Box $/ \mathrm{m}^{2} /$ tahun \\
\hline Internasional & 249.777 & 499 & 10 \\
\hline Domestik & 329.959 & 733 & 24
\end{tabular}

Sumber: Data Analisis 2020

Dari tabel 4 dapat diketahui bahwa Daya Lalu Petikemas (BTP) di Dermaga Internasional yaitu 499 box $/ \mathrm{m} /$ tahun atau $10 \mathrm{box} / \mathrm{m}^{2} /$ tahun dan pada Dermaga Domestik yaitu 733 box $/ \mathrm{m} /$ tahun atau $24 \mathrm{box} / \mathrm{m}^{2} / \mathrm{tahun}$.

\section{KESIMPULAN}

Berdasarkan pengamatan dan hasil analisis waktu bongkar muat alat Ship to shore (STS) crane di Terminal Teluk Lamong yang telah dilakukan dengan uraian yang telah dibahas pada bab sebelumnya, maka dapat ditarik kesimpulan bahwa:

1. Effective time tertinggi proses bongkar terjadi pada STS 03I mencapai 2012 detik atau 33 menit 32 detik dan Effective time tertinggi pada proses muat terjadi pada STS 03I mencapai 2208 detik atau 36 menit 48 detik. Idle time tertinggi proses bongkar terjadi pada STS 05I mencapai 908 detik atau 15 menit 8 detik dan Idle time tertiggi pada proses muat terjadi pada STS 02I mencapai 796 detik atau 13 menit 16 detik. Waktu yang terbuang atau waktu tidak produktif selama proses bongkar muat disebabkan oleh waktu menunggu muatan datang dari container yard, Ship to shore (STS) crane peralatan bongkar muat rusak, pengaruh cuaca saat hujan yang mengakibatkan jarak pandang operator terganggu sehingga proses bongkar muat dihentikan untuk sementara

2. Hasil dari rekapitulasi kinerja pelayanan Ship to shore (STS) crane tertinggi pada STS 01I pada saat proses bongkar didapatkan 24 box/STS/jam, dan rata-rata terendah dari hasil rekapitulasi pada STS 05I saat proses bongkar didapatkan sebanyak 19 box/STS/jam. Pada proses muat hasil rekapitulasi kinerja pelayanan Ship To Shore Crane tertinggi pada STS 04D didapatkan sebanyak 24 box/STS/jam, dan rata-rata terendah dari hasil rekapitulasi pada STS 03I saat proses muat didapatkan sebanyak 18 box/STS/jam.

3. Daya Lalu Petikemas (BTP) di Terminal Teluk Lamong pada Dermaga Internasional didapatkan sebanyak $499 \mathrm{box} / \mathrm{m}$ atau 10 box/m2 dan pada Dermaga Domestik yaitu 733 box $/ \mathrm{m}$ atau 24 box $/ \mathrm{m}^{2}$

\section{DAFTAR PUSTAKA}

[1] Budiyanto, Eko Hariyadi, dan Raja Oloan Saut Gurning. (2017). Manajemen Pelabuhan. Surabaya: PT. Andhika Prasetya Ekawahana.

[2] Triatmodjo, B, "Perencanaan Pelabuhan" Yogyakarta: Beta Offset, 2010

[3] Kramadibrata, S. (2002). Perencanaan Pelabuhan. Bandung: ITB.

[4] Lasse, D.A (2012). Manajemen Peralatan Aspek Operasional dan Perawatan. Jakarta: PT Raja Grafindo Persada.

[5] Lasse, D.A (2012). Manajemen Muatan, Aktivitas Rantai Pasok Di Area Pelabuhan. Banjarmasin: Rajawali Pers.

[6] Lasse, D.A (2014). Manajemen Kepelabuhanan. Jakarta: PT Raja Grafindo Persada.

[7] Mandi, N. B. (2015). Pelabuhan Perencanaan dan Perancangan Konstruksi Bangunan Laut dan Pantai. Denpasar: Buku Arti.

[8] Oblak, R., Bistricic, A. \& Jugovic, A. (2013). Public Private Partnership Management Model of Croatian Seaports. Management, Diakses dari https://hrcak.srce.hr/file/153270 pada Februari 2020 